\title{
Social, Economic and Environment Sustainability of Food Crop Production Systems: Sugarcane vs. Maize Production
}

\author{
Weerakkody P.R. ${ }^{1 *}$, Gunawardene U.A.D.P. ${ }^{2}$, Dunusinghe P.M. ${ }^{3}$ \\ ${ }^{1}$ Hector Kobbekaduwa Agrarian Research \& Training Institute, Sri Lanka \\ ${ }^{2}$ Department of Forestry \& Environmental Science, University of Sri Jayewardenepura, Sri Lanka \\ ${ }^{3}$ Department of Economics, University of Colombo, Sri Lanka \\ *renukaweerakkody28@gamil.com
}

\begin{abstract}
Knowledge and technological inputs have played a significant role in the process of agrarian transformation of low input subsistence farming to high input commercial systems. The said transformation took place at a varying degree and nature owing to policy interests of successive governments though succeeded in meeting the growing food demand it eventually led to serious socio-economic and environmental implications and made food crop production systems (FCCPSs) more unsustainable. Many of them are irreversible and restoring the lost socio-economic values and degraded eco systems are challenging. Therefore, it has been a greater challenge today to achieving key sustainable development goals - Zero Poverty and No Hunger- while making FCPSs of small farmers sustainable. Identification of and encouraging wide-spread adoption of sustainable FCPSs is a must for that reason where policy directives could play a significant role. This study analyses and presents how effective are the agricultural sustainability indices as decision tools in the above mission. Primary data collected from two rain-fed FCPSs -maize and sugarcane- in the South East Dry Zone of Sri Lanka (SEDZ) in 2016 were used to assess the sustainability indices based on ten variables representing social, economic and environmental dimensions of sustainability of the FCPSs. The sample involved 149 farmers from Pelawatta sugarcane settlement scheme in Monaragala District and 130 maize farmers from Monaragala and Ampara districts. Additional data were collected through key informant interviews, focus group discussions and field observations. The results of the study showed that, both crops demonstrates approximately equally in social (SSI: maize - 0.566, sugarcane - 0.562) and environmental terms (ESI: maize - 0.260 and sugarcane - 0.259). Use of agrochemicals for weed control and fertilizer to compensate depleting soil fertility has become inescapable in both crops. Crop yield reduction owing to poor quality planting material is a major implication too. However, sugarcane is financially better off (FSI: 0.491) than maize (FSI: 0.342). Among the contributing variables were; higher contribution to family income (70 percent) and considerably high productivity (18850 $\mathrm{kg} / \mathrm{ac} / \mathrm{yr}$ ) in compared to that of maize -38 percent and $1764 \mathrm{~kg}$ of maize/ac/yr respectively. Currently there is a growing interest towards the expansion of croplands for both crops yet, the government is indecisive on the allocation of precious land resources. Therefore, the implications of the study contributes further dimensions to face the challenge of ending hunger and poverty through allocating land and other resources towards promoting sustainable FCPSs.
\end{abstract}

Keywords: Agrarian transformation, Food crops, Sustainability, Policy directives, Resource allocation

Proceedings of the $22^{\text {nd }}$ International Forestry and Environment Symposium 2017 of the Department of Forestry and Environmental Science, University of Sri Jayewardenepura, Sri Lanka 